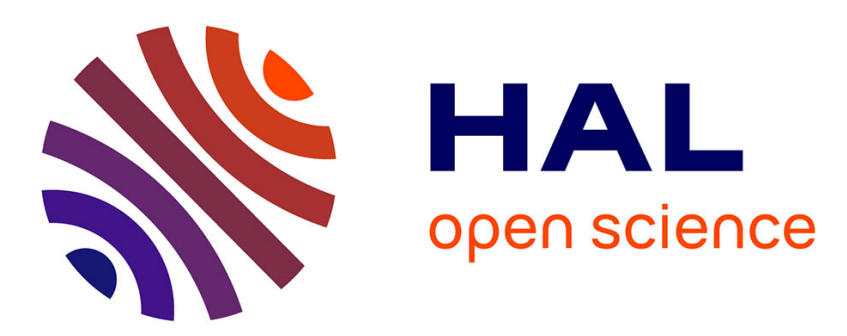

\title{
Statistical approach to lorig-term performances of photovoltaic systems
}

B. Bartoli, U. Coscia, V. Cuomo, F. Fontana, V. Silvestrini

\section{To cite this version:}

B. Bartoli, U. Coscia, V. Cuomo, F. Fontana, V. Silvestrini. Statistical approach to lorig-term performances of photovoltaic systems. Revue de Physique Appliquée, 1983, 18 (5), pp.281-285. 10.1051/rphysap:01983001805028100 . jpa-00245092

\section{HAL Id: jpa-00245092 https://hal.science/jpa-00245092}

Submitted on 1 Jan 1983

HAL is a multi-disciplinary open access archive for the deposit and dissemination of scientific research documents, whether they are published or not. The documents may come from teaching and research institutions in France or abroad, or from public or private research centers.
L'archive ouverte pluridisciplinaire HAL, est destinée au dépôt et à la diffusion de documents scientifiques de niveau recherche, publiés ou non, émanant des établissements d'enseignement et de recherche français ou étrangers, des laboratoires publics ou privés. 
Classification

Physics Abstracts

$86.10 \mathrm{~K}-86.30 \mathrm{~J}$

\title{
Statistical approach to long-term performances of photovoltaic systems
}

\author{
B. Bartoli, U. Coscia, V. Cuomo, F. Fontana and V. Silvestrini \\ Istituto di Fisica della Facoltà di Ingegneria, Università di Napoli, Piazzale Tecchio, Napoli, Italy
}

(Reçu le 11 octobre 1982, révisé le 24 janvier 1983, accepté le 4 février 1983)

\begin{abstract}
Résumé. - Dans cet article nous exposons un modèle analytique capable de décrire les performances d'un système photovoltaïque. Ce modèle lie le rendement du système avec les variables du problème les plus significatives : les dimensions du système et les paramètres météorologiques. Enfin nous étudions le niveau de confiance de notre modèle et les limites de son applicabilité.
\end{abstract}

\begin{abstract}
In this paper we propose an analytical model able to describe long-term performances of a photovoltaic system. Such a model relates efficiency of the system with the more meaningful variables involved in the problem : system sizes and meteorological parameters. Furthermore we study the reliability of our model and the limits of its usefulness.
\end{abstract}

1. Introduction. - Let us consider the photovoltaic (ph.v.) system schematically shown in figure 1. The performances of such a device can be analysed to any degree of detail by means of computer simulation programs; however, this analysis becomes more costly as it becomes more sophisticated.

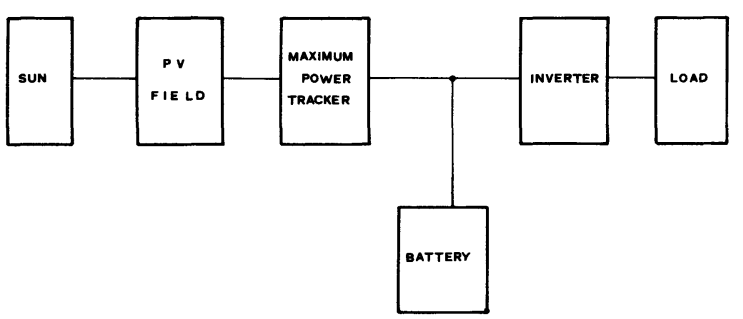

Fig. 1. - Schematic drawing of the ph.v. system analysed.

In previous papers it has been shown that :

1. Simulation programs based on a daily energy balance provide results which are in practice as good as the programs based on an instantaneous analysis in terms of power [1].

2. The results of the simulation programs can be put in a quite simple analytic form in terms of a small number of quantities which represent the size and the technical properties of the system [2]. This approach allows a drastic simplification of the procedure of matching the size of the system to the energy demand of the user.
In this paper we perform a deeper analysis of the analytic approach. The main results of this analysis are the followings :

i) it demonstrates that the fluctuations of the performances of the system around the average value can be fully interpreted in terms of statistical fluctuations of the meteorological input data. The analytical approach has therefore the maximum possible predictive power compatible with the statistical properties of the solar energy impinging into the photovoltaic field;

ii) it allows us to determine the numerical value of the parameters of the model.

2. The model. - Let us define the quantity

$$
y_{\mathrm{m}}=\frac{L_{\mathrm{mc}}}{L_{\mathrm{mT}}} \quad(\mathrm{m}=1, \ldots, 12)
$$

where $L_{\mathrm{mT}}$ is the daily energy demand (load) which we assume to be constant during each month; and $L_{\mathrm{mc}}$ is the monthly average of the daily energy which the photovoltaic system supplies to the load. $y_{\mathrm{m}}$ represents therefore the average fraction of the load covered by the ph.v. system during the mth month.

As a consequence of the above remark 1 we can write :

$$
\begin{gathered}
y_{\mathrm{m}}=y\left(A, C, \eta_{\mathrm{PC}}, \eta_{\mathrm{PT}}, \eta_{\mathrm{B}}, \eta_{\mathrm{l}}, L_{\mathrm{mT}}, E_{\mathrm{mc}}, K_{\mathrm{Tmi}}, D_{\mathrm{mi}}\right) \\
(\mathrm{i}=1, \ldots, 30)
\end{gathered}
$$


where

$A=$ useful area of the ph.v. array

$C \quad=$ battery storage capacity

$\eta_{\mathrm{PC}}=$ efficiency of the ph.v. cells

$\eta_{\mathrm{PT}}=$ efficiency of the maximum power tracker

$\eta_{\mathrm{I}} \quad=$ efficiency of the inverter

$\eta_{\mathrm{B}}=$ efficiency of the storage battery

$D_{\text {mi }}=$ time-length of the day of the mth month (sunrise to sunset)

$K_{\mathrm{Tmi}}=\frac{E_{\mathrm{mi}}}{E_{\mathrm{mc}}}$

$E_{\mathrm{mi}}=$ daily solar radiation impinging on horizontal surface (ith day of the mth month)

$E_{\mathrm{mc}}=$ daily extra-atmospheric radiation on horizontal surface, monthly average (mth month).

In a previous paper [3] it has been shown that the statistical properties of the sample of the $K_{\mathrm{Tmi}}$ $(i=1, \ldots, 30)$ are fully determined by their monthly average $K_{\mathrm{Tm}}$

$$
K_{\mathrm{Tm}}=\frac{\sum_{\mathrm{i}=1}^{30} K_{\mathrm{Tmi}}}{30}
$$

Thus we have :

$$
y=y\left(A, C, \eta_{\mathrm{PC}}, \eta_{\mathrm{PT}}, \eta_{\mathrm{I}}, \eta_{\mathrm{B}}, L_{\mathrm{mT}}, E_{\mathrm{mc}}, K_{\mathrm{Tm}}, D_{\mathrm{m}}\right)
$$

where $D_{\mathrm{m}}$ is the monthly average of $D_{\mathrm{mi}}$.

On the basis of scaling arguments discussed in reference [2], it is to be expected that $y_{\mathrm{m}}$ depends only on the following combinations of the parameters $A, C, \eta_{\mathrm{PT}}, \eta_{\mathrm{PC}}, \eta_{\mathrm{I}}, L_{\mathrm{mT}}, E_{\mathrm{mc}}$

$X_{\mathrm{m}}=$ average daily energy supplied by the ph.v. systems normalized to the load

$$
X_{\mathrm{m}}=A \eta_{\mathrm{PC}} \eta_{\mathrm{PT}} \eta_{\mathrm{I}} \frac{E_{\mathrm{mc}}}{L_{\mathrm{mT}}}
$$

$$
\Gamma_{\mathrm{m}}=\text { storage capacity normalized to the load }
$$

$$
\Gamma_{\mathrm{m}}=\frac{C}{L_{\mathrm{mT}}} \eta_{\mathrm{B}},
$$

therefore :

$$
y_{\mathrm{m}}=y\left(X_{\mathrm{m}}, \Gamma_{\mathrm{m}}, K_{\mathrm{Tm}}, D_{\mathrm{m}}\right) .
$$

From physical considerations, we also expect the following limit conditions to hold :

$$
\begin{aligned}
& \lim _{x_{\mathrm{m}} \rightarrow \infty} y_{\mathrm{m}}=1 \quad\left(\text { if } \Gamma_{\mathrm{m}} \gg 1\right), \\
& y_{\mathrm{m}}=\eta_{\mathrm{B}} X_{\mathrm{m}} \quad\left(\text { if } X_{\mathrm{m}} \ll 1\right) .
\end{aligned}
$$

Condition (7) claims that when the storage capacity is as large as required to cover the load for some days $\left(\Gamma_{\mathrm{m}} \gg 1\right)$, a large enough ph.v. field is able to cover completely the load $\left(X_{\mathrm{m}} \rightarrow \infty\right)$; while condition (8) claims that in the case of a small ph.v. field all the energy produced by the ph.v. system can be usefully transferred to the load.

A simple curve satisfying the above limit conditions is the hyperbola

$$
\left(y_{\mathrm{m}}-1\right)\left(y_{\mathrm{m}}-\eta_{\mathbf{B}} X_{\mathrm{m}}\right)=\gamma,
$$

where $\gamma$ represents a free function of the model, to be determined by the simulation procedure. In principle, $\gamma$ can be a function of $D_{\mathrm{m}}, K_{\mathrm{Tm}}$ and $\Gamma_{\mathrm{m}}$. However, on the basis of scaling considerations discussed in reference [2], we more precisely expect that $\gamma$ is a function of the product $K_{\mathrm{Tm}} \cdot D_{\mathrm{m}}$ and of $\Gamma_{\mathbf{m}}$.

In reference [2], the simplest possible expression

$$
\gamma=K_{\mathrm{Tm}} \cdot D_{\mathrm{m}} \cdot \Gamma_{\mathrm{m}}
$$

has been proposed. However, the statistical analysis presented in the next section will provide a somewhat more complicated form for $\gamma$, so that equation (10) must be taken as a rough approximation. In our analysis we always used the $\chi^{2}$-test at a confidence level of $95 \%$.

3. The parameters of the model. - The validity of equation (9) has been shown in reference [2]. Here we want to determine the dependence of $\gamma$ on $K_{\mathrm{Tm}} \cdot D_{\mathrm{m}}$ and on $\Gamma_{\mathrm{m}}$. To this aim, we have proceeded as follows.

Using the historical daily climatic data of a given month in 18 localities chosen among the meteorological stations of the "Aeronautica Militare Italiana " [4], uniformly spread all over Italy, we run the simulation program for different values of $X_{\mathrm{m}}$. Since $D_{\mathrm{m}} \cdot K_{\mathrm{Tm}}$ is determined, once the month and the locality have been chosen, $X_{\mathrm{m}}$ is varied by varying the area $A$ of the photovoltaic field. Fixing a numerical value $\bar{\gamma}$ for $\gamma$ of equation (9), we repeat the above simulation procedure for many values of $\Gamma_{\mathrm{m}}$, until we find the value $\gamma$ which fits better the hyperbola characterized by $\bar{\gamma}$. Typical results of this analysis are presented in figures 2 and 3 . In table I we sum-

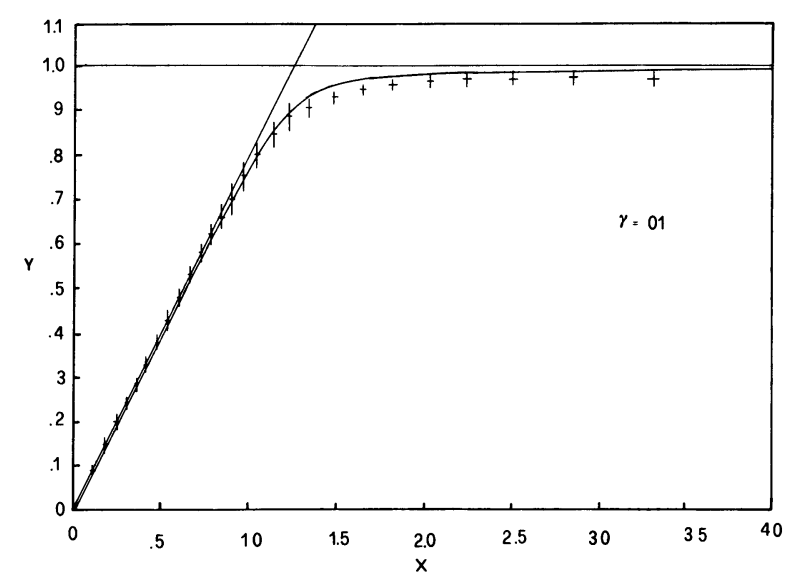

Fig. 2. - Covered load fraction $y_{\mathrm{m}}$ as a function of the parameter $X$. The parameter is $\gamma=0.01$. 

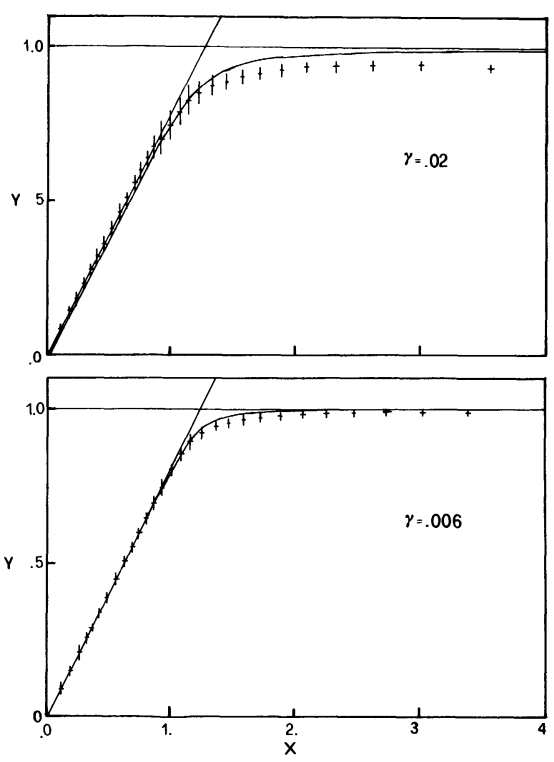

Fig. 3. - The fraction $y_{m}$ of the load covered by the ph.v. system as a function of $X_{\mathrm{m}}$ (parameter $\gamma$ ).

\section{Table I}

$\begin{array}{cc}\gamma \times 10^{-2} & \frac{\chi^{2}}{-} \\ 0.2 & 1.32 \\ 0.4 & 1.34 \\ 0.6 & 1.60 \\ 0.8 & 1.67 \\ 1.0 & 1.30 \\ 1.2 & 1.65 \\ 1.4 & 1.77 \\ 1.6 & 1.95 \\ 1.8 & 2.35 \\ 2.0 & 4.30 \\ 2.5 & 5.10 \\ 3.0 & \\ 3.2 & >6 \\ 3.4 & \end{array}$

marize the numerical results of the $\chi^{2}$-test. As we see, the model works well up to values of $\gamma$ of $\simeq 1.5 \times 10^{-2}$.
Repeating the above procedure for all the different localities and all the months, we determine in this way the dependence of $\Gamma_{\mathrm{m}}$ on $D_{\mathrm{m}} \cdot K_{\mathrm{Tm}}$ for each value of the parameter $\gamma$. Typical results are presented in figure 4 . This approach is particularly convenient from the point of view of applications. In fact $\gamma$ is closely related to the performance of the system, since $\sqrt{\gamma}$ represents the fraction of the load which is left uncovered by the system in the given month for $X_{\mathrm{m}}=1$. The curves of figure 4 allow thus the evaluation of the storage capacity $C$ which is needed to obtain the goal value of $\sqrt{\gamma}$. The condition $\gamma<1.5 \times 10^{-2}$, corresponds to the requirement that if we want the model to be valid the storage capacity must be typically larger than the daily load.

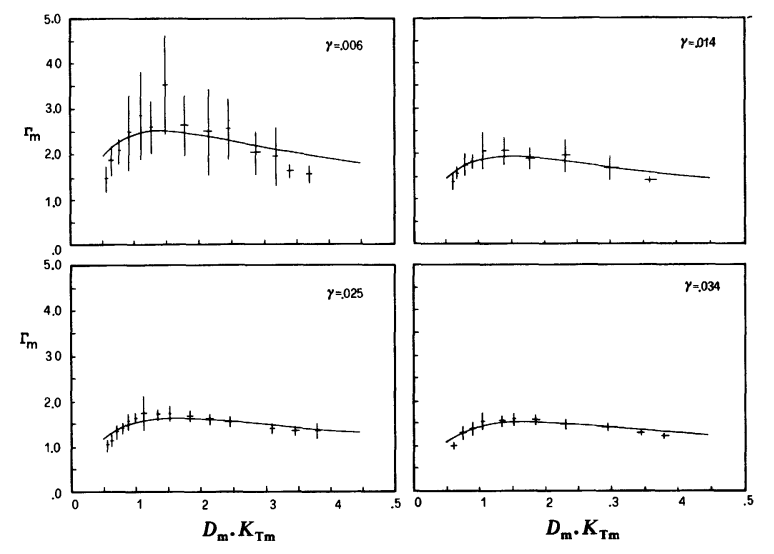

Fig. 4. - The normalized storage capacity $\Gamma_{\mathrm{m}}$ versus the variable $D_{\mathrm{m}} \cdot K_{\mathrm{Tm}}$ (parameter $\left.\gamma\right)$.

By applying the best fit procedure to the data points of figure 4 , we have determined the following analytical form for $\Gamma_{\mathrm{m}}$ :

$$
\Gamma_{\mathrm{m}}=\frac{a\left(D_{\mathrm{m}} \cdot K_{\mathrm{Tm}}\right)}{\left(b+\left(D_{\mathrm{m}} \cdot K_{\mathrm{Tm}}\right)\right)^{2}},
$$

where $a$ and $b$ have the following dependence on $\gamma$ (see Fig. 5) :

$$
\begin{array}{lll}
a=\alpha_{1} \cdot \exp \left(-\gamma \cdot \beta_{1}\right)+1 & \alpha_{1}=0.695 \pm 0.035 & \beta_{1}=71.2 \pm 5.7 \\
b=\alpha_{2} \cdot \gamma^{\beta_{2}} & \alpha_{2}=0.274 \pm 0.008 & \beta_{2}=0.136 \pm 0.006
\end{array}
$$

where the fits (11) and (12) are independent of the values of $m$ (i.e. they do not depend on season).

The numerical results of the $\chi^{2}$-test applied to the best fit curves of figure 4 are presented in table II. As we see, the statistical consistency is completely satisfactory.

In some cases, it may be useful to know the function $\gamma=\gamma\left(\Gamma_{\mathrm{m}}, D_{\mathrm{m}} \cdot K_{\mathrm{Tm}}\right)$ rather than $\Gamma_{\mathrm{m}}=\Gamma_{\mathrm{m}}\left(\gamma, D_{\mathrm{m}} \cdot K_{\mathrm{Tm}}\right)$. Mathematically, the inversion of $\Gamma_{\mathrm{m}}$ does not lead to a useful expression. We have thus used a statistical procedure.

The analytical expression of $\gamma\left(\Gamma_{\mathrm{m}}, D_{\mathrm{m}} \cdot K_{\mathrm{Tm}}\right)$ resulting from the best fit procedure to the data points of figure 6 is :

$$
\gamma=\frac{a^{\prime}\left(D_{\mathrm{m}} \cdot K_{\mathrm{Tm}}-0.05\right)}{\left(b^{\prime}+D_{\mathrm{m}} \cdot K_{\mathrm{Tm}}-0.05\right)}
$$



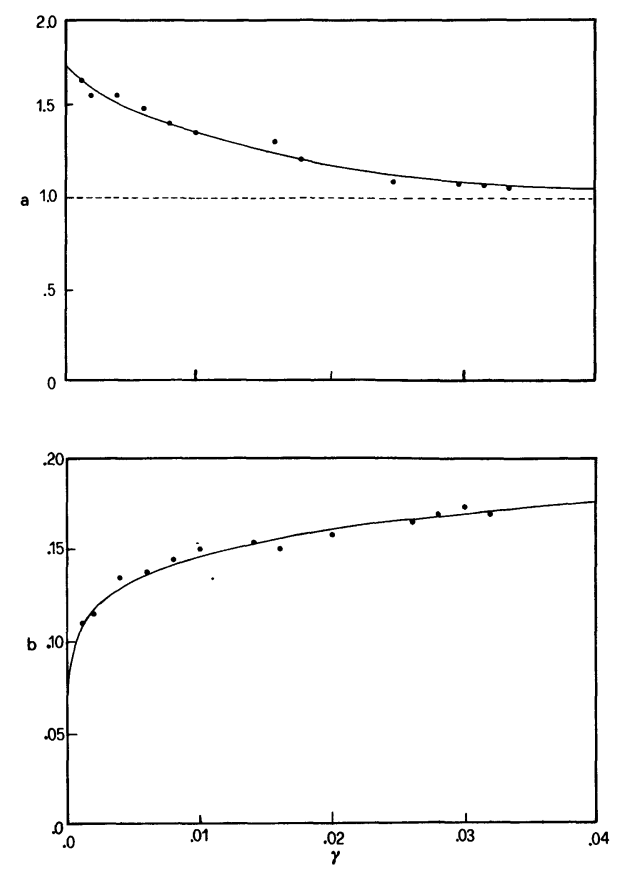

Fig. 5. - The parameters $a$ and $b$ versus $\gamma$.

Table II

$\begin{array}{cc}\gamma \times 10^{-2} & \frac{\chi^{2}}{-} \\ 0.2 & 2.20 \\ 0.4 & 2.30 \\ 0.6 & 1.45 \\ 0.8 & 1.25 \\ 1.0 & 1.10 \\ 1.2 & 1.30 \\ 1.4 & 1.80 \\ 1.6 & 2.30 \\ 1.8 & 2.34 \\ 2.0 & 2.83\end{array}$

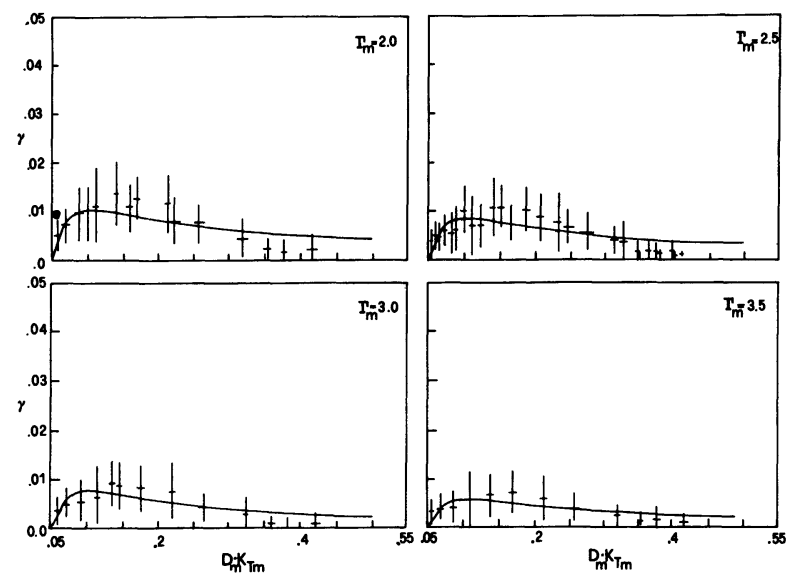

Fig. 6. - The behaviour of $\gamma$ versis $D_{\mathrm{m}} \cdot K_{\mathrm{Tm}}\left(\right.$ parameter $\left.\Gamma_{\mathrm{m}}\right)$. where $a^{\prime}$ and $b^{\prime}$ have the following dependence on $\Gamma_{\mathrm{m}}$ (see Fig. 7)

$$
\begin{array}{ll}
a^{\prime}(\Gamma)=\alpha_{1}^{\prime} \Gamma^{-\beta_{1}^{\prime}}+\delta_{1}^{\prime} & \alpha_{1}^{\prime}=0.0058 \pm 0.0003 \\
& \beta_{1}^{\prime}=4.93 \pm 0.10 \\
& \delta_{1}^{\prime}=10^{-3} \pm 0.0001 \\
b^{\prime}(\Gamma)=\alpha_{2}^{\prime} \Gamma^{-\beta_{2}^{\prime}}+\delta_{2}^{\prime} & \alpha_{2}^{\prime}=0.103 \pm 0.0046 \\
& \beta_{2}^{\prime}=4.05 \pm 0.33 \\
& \delta_{2}^{\prime}=0.005 \pm 0.0002
\end{array}
$$
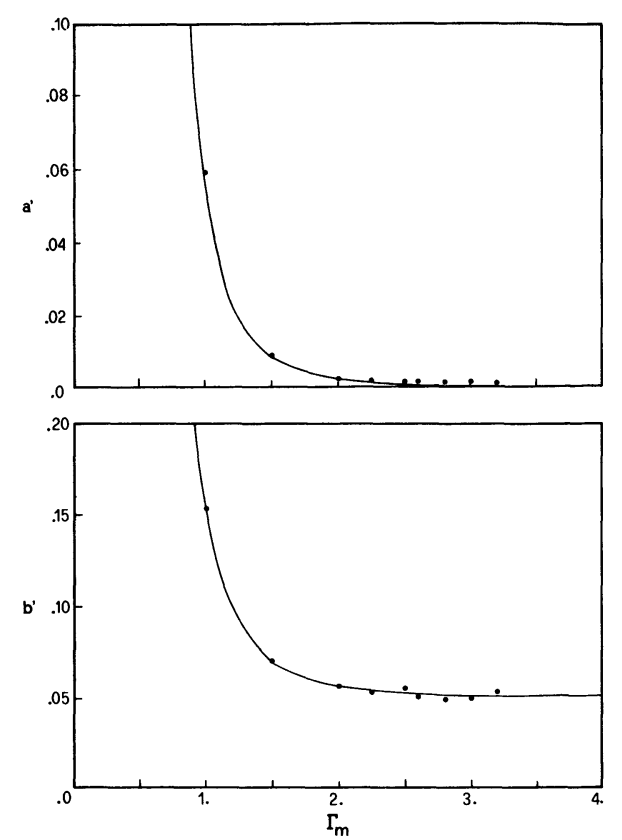

Fig. 7. - The parameters $a^{\prime}$ and $b^{\prime}$ versus $\Gamma_{\mathrm{m}}$.

Table III gives the numerical results of the $\chi^{2}$-test applied to the best fit of figure 6 , these fits also are independent of the values of $\mathrm{m}$.

Table III

$\begin{array}{cc}\frac{\Gamma}{-} & \frac{\chi^{2}}{1.4} \\ 1.6 & 2.80 \\ 1.8 & 2.32 \\ 2.2 & 2.20 \\ 2.4 & 1.90 \\ 2.8 & 1.85 \\ 3.0 & 1.80 \\ 3.2 & 1.65 \\ 3.4 & 1.40 \\ 3.6 & 1.50 \\ 3.8 & 1.94 \\ 4.0 & 1.98 \\ 4.5 & 2.05 \\ 5.0 & 2.00 \\ & 2.10\end{array}$


4. Independence of the model on the locality. The results of the $\chi^{2}$-tests already show that the parameters of our model are independent of the locality, at least in the Italian climate. In fact, for the previously reported analysis we have put together, as already mentioned, climatic data referring to localities rather uniformly spread on the Italian Territory.

For a further test of this crucial point, we have run the simulation procedure in some other Italian Stations different from those used in our previous analysis, i.e. not used for the determination of the fits and of the parameters; and we have finally com-

Table IV

$\begin{array}{cc}\gamma \times 10^{-2} & \frac{\chi^{2}}{-} \\ 0.2 & 2.20 \\ 0.4 & 1.17 \\ 0.6 & 1.51 \\ 0.8 & 1.33 \\ 1.0 & 1.65 \\ 1.2 & 1.90 \\ 1.4 & 2.05 \\ 1.6 & 2.35 \\ 1.8 & 2.40 \\ 2.0 & 2.90\end{array}$

pared the new data points obtained in this way with the prediction of the model.

In table IV we present the numerical results of the $\chi^{2}$-test applied to this comparison.

Once again, the statistical consistency is fully satisfactory.

5. Conclusions. - Our statistical analysis shows that long-term performances of photovoltaic systems can be described by means of simple analytic functions.

In fact, the fraction $y_{\mathrm{m}}$ of the load monthly covered by the system is well described by an hyperbola $y_{\mathrm{m}}=y\left(X_{\mathrm{m}}, \gamma\right)$, where $X_{\mathrm{m}}$ is the montly average yield of the photovoltaic field normalized to the monthly average of the load. The only free parameter $\gamma$ of the hyperbola is a function of the battery storage capacity $C$ and of the average availability of solar energy during the considered month.

The explicit form of $\gamma$ as a function of the relevant parameters has been determined. Such a function is independent of the locality, at least in the Italian climate.

As a net result of all these conclusions, the optimal sizing of photovoltaic systems can be performed in a very simple way by means of straightforward hand calculations.

\section{References}

[1] Ambrosone, G., Catalanotti, S., Cocurullo, G. Coscia, U., Troise, G., Comparison between a sophisticated and an approximated method of analysis of a photovoltaic system sent for publication to Solar Energy.

[2] Barra, L., Catalanotti, S., Fontana, F., LavoRANTE, F., An analytical method to determine the optimal size of a photovoltaic plant sent for publication to Solar Energy.
[3] Bartoli, B., Catalanotti, S., Cuomo, V., FrancesCA, M., Serio, C., Silvestrini, V., Troise, G., Nuovo Cimento 2C (1979) 222.

[4] Aeronautica Militare della Repubblica Italiana, Ispettorato Telecomunicazioni ed Assistenza al Volo, III Rep., Servizio Meteorologico Roma : Durata del sole e radiazione globale Nota tecnica no. 19, Roma 1970. 